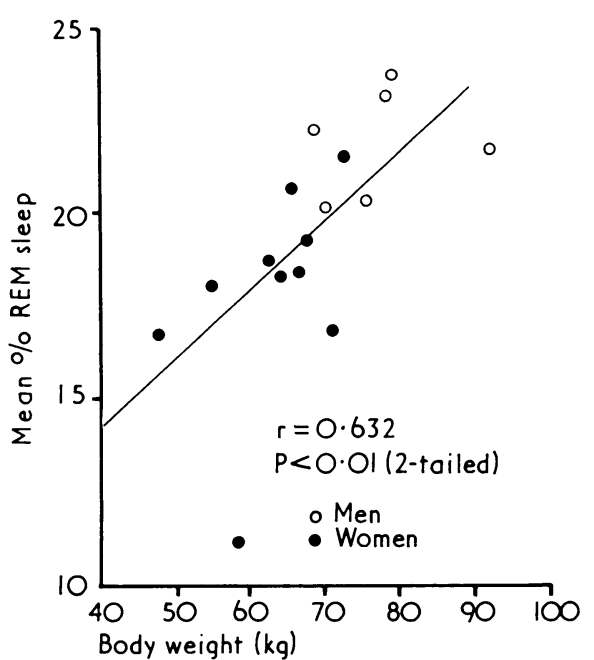

Simple correlation between body weight and percentage of REM sleep.

In rats the amount of REM sleep in a $12 \mathrm{~h}$ period accurately predicted food intake in the subsequent $12 \mathrm{~h} .{ }^{4}$ These observations are consistent with the present finding and since log body weight is highly correlated with the daily metabolic rate ${ }^{5}$ it seems likely that REM sleep is closely linked to general body metabolism and restitution.

I would like to thank Dr Ian Oswald and Beecham Products Ltd for their help.

${ }^{1}$ British Medical fournal, 1976, 2, 1523.

${ }^{2}$ Lacey, J H, et al, British Medical fournal, 1975, 4, 556

${ }^{3}$ MacFadyen, U M, Oswald, I, and Lewis, S A, fournal of Applied Physiology, 1973, 35, 391.

${ }^{4}$ Siegel, J M, Physiology and Behavior, 1975, 15, 399.

${ }^{5}$ Kleiber, M, The Fire of Life: an Introduction to Animal Energetics. New York, John Wiley and Sons, 1961.

(Accepted 10 December 1976)

University Department of Psychiatry, Royal Edinburgh Hospital, Edinburgh EH10 5HF

KIRSTINE ADAM, BSC, research associate

\section{Pseudotumours of the pancreas}

A mass felt in the pancreas at laparotomy is normally regarded as a tumour and, indeed, it usually is. Three tumour-like lesions of the pancreas have recently been encountered in this hospital, one of which was treated by a pancreaticoduodenectomy. All three showed the same distinctive histology, which does not appear to have been reported.

\section{Case reports}

Case 1-A 46-year-old man was admitted for surgical treatment of a chronic duodenal ulcer and gall stones. At laparotomy the presence of a duodenal ulcer and of gall stones was confirmed, but there was also a discreet hard mass in the head of the pancreas, which was considered to be a carcinoma. The liver was abnormal and a wedge biopsy was taken. A pancreaticoduodenectomy was performed with a cholecystectomy. Recovery from the operation was uneventful. Pathological examination showed a well-defined ovoid mass $1.6 \times 0.8 \mathrm{~cm}$ on the superior border of the head of the pancreas. Microscopically, the lesion consisted of lobulated connective tissue enclosing irregular, branching pancreatic ducts, acinar tissue, and islet cells in a disorderly arrangement (figure). Multiple blocks taken from other areas of the pancreas showed a few tiny nodules of similar appearance. There was no evidence of pancreatitis. The liver biopsy taken at operation showed partial nodular transformation.

Case 2-A 35-year-old man gave a five-year history of recurrent attacks of epigastric pain due to chronic pancreatitis. An endoscopic retrograde pancreatogram showed a blocked pancreatic duct. At laparotomy the tail of the pancreas was removed and an antegrade pancreatogram, which showed a normal pancreatic duct, was performed. Histology of the tail of the pancreas showed mild chronic pancreatitis with intra- and interlobular fibrosis and patches of old fat necrosis. There were also multiple discreet nodules of duct proliferation surrounded by fibrosis similar to those seen in case 1 .

Case 3-A 58-year-old man died of disseminated malignant lymphoma. There had been no symptoms or signs of gastrointestinal or pancreatic disease. At routine necropsy a $1.0 \times 0.5 \mathrm{~cm}$ solitary nodule was found in the head of the pancreas. Histological examination of this lesion showed a lobulated mass of loose connective tissue enclosing dilated pancreatic ducts with acinar and islet cells. The lesion was again well circumscribed and it appeared to be associated with stenosis of a major duct.

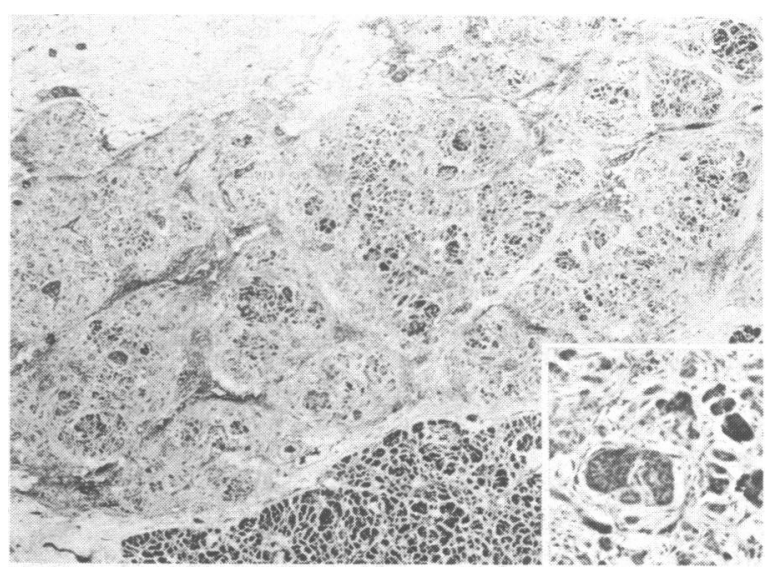

Pseudotumour of the pancreas (case 1): a well-defined mass made up of lobulated connective tissue enclosing ducts and acinar and islet cells in complete disarray. (Haematoxylin-eosin. $\times 5$, insert $\times 50$.)

\section{Discussion}

Histology of the lesion in all three cases showed lobulated connective tissue surrounding acinar cells and pancreatic ducts. In cases 1 and 3 islet cells were present. The general appearances suggested a malformation or hamartoma, and, moreover, in case 1 the liver showed partial nodular transformation-a condition also considered to be hamartomatous. ${ }^{1} \mathrm{~A}$ computer-aided search of published reports has failed to find a report of pancreatic hamartomas other than those which are lymphovascular in origin and are readily detectable as such. ${ }^{23}$ Cases 2 and 3 were associated with duct stenosis, and possibly this may lead to pancreatitis which then may be focal or generalised, depending on the level and size of duct affected. Pancreatitis was seen in case 2 but was absent in cases 1 and 3. For the time being, the most appropriate designation of these lesions would be "pseudotumour."

The condition may be commoner than the absence of documentation suggests, and may be an important source of diagnostic error at laparotomy. Indeed, some of the long-term survivors after palliative procedures for carcinoma may have had a pseudotumour. Such lesions should be easily distinguished by a thin needle biopsy, which can be performed safely at the time of operation. ${ }^{4}$

1 Edmondson, $\mathrm{H}$ A, in Hepatocellular Carcinoma, ed by K Okuda and R L Peters, p 309. New York, Wiley, 1976.

2 Pages, A, Marty-Double, Ch, and Baldet, P, Archives d'Anatomie Pathologique, 1972, 3, 303.

${ }^{3}$ Roe, M, and Greenough, W G, Radiology, 1974, 113, 47.

${ }^{4}$ Reuben, A, and Cotton, P B, Annals of the Royal College of Surgeons of England, 1976, in the press.

(Accepted 10 December 1976)

\section{The Middlesex Hospital, London W1}

P P ANTHONY, MRCPATH, senior lecturer and honorary consultant pathologist

R G FABER, FRcs, lecturer in surgery

R C G RUSSELL, FRCS, consultant surgeon 